\title{
ПРИМЕНЕНИЕ АМНИОТИЧЕСКОЙ МЕМБРАНЫ В ЛЕЧЕНИИ ДИАБЕТИЧЕСКИХ ЯЗВ СТОПЫ (ОБЗОР ЛИТЕРАТУРЫ)
}

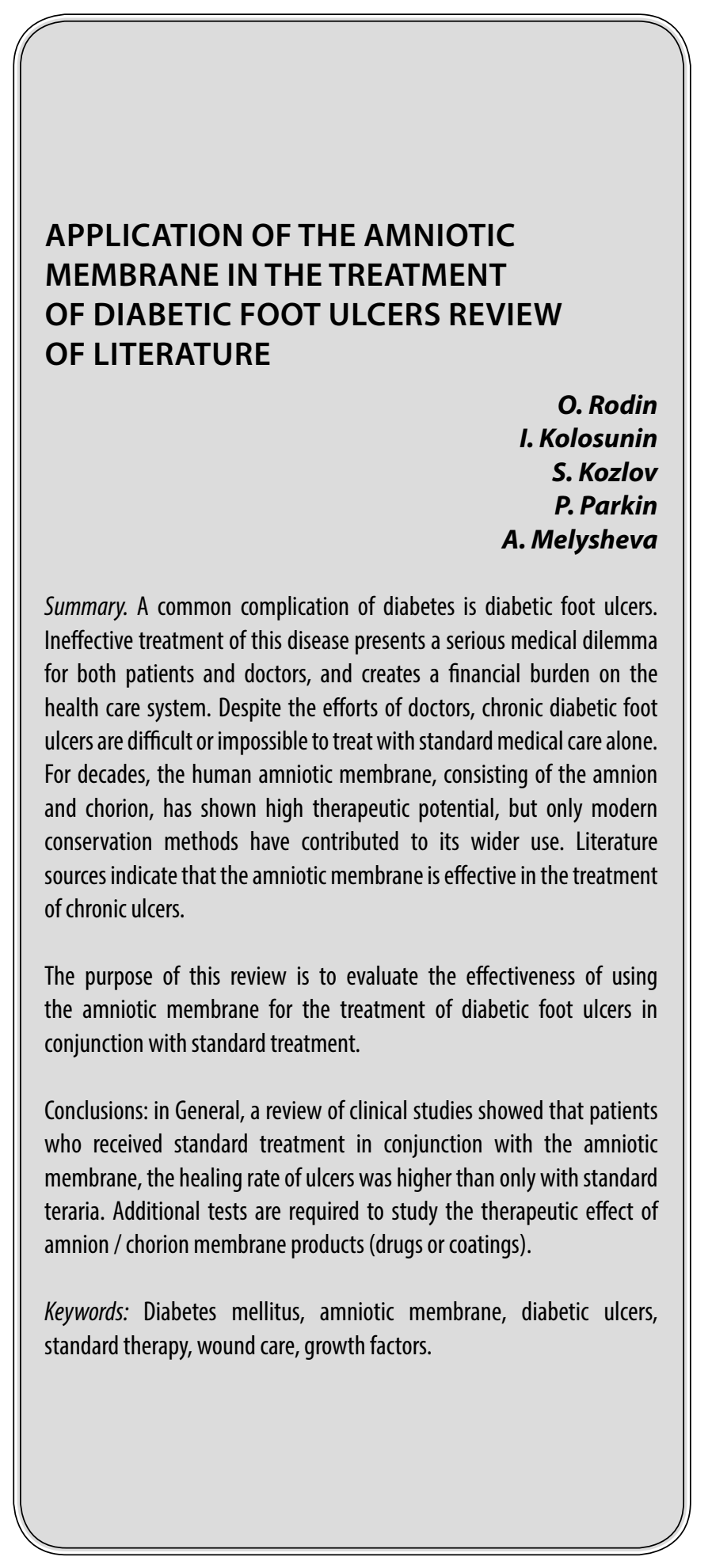

\author{
Родин Олег Васильевич \\ ФГБОУ ВО «Начиональный исследовательский \\ Мордовский государственный университет \\ им. Н.П. Огарева» \\ rodin1oleg@gmail.com \\ Колосунин Иван Александрович \\ ФГБОУ ВО «Национальный исследовательский \\ Мордовский государственный университет \\ им. Н.П. Огарева» \\ kolosunin_ivan@mail.ru \\ Козлов Сергей Александрович \\ Д.м.н., профессор, ФГБОУ ВО «Начиональный \\ исследовательский Мордовский государственный \\ университет им. Н. П. Огарева» \\ kozlovsa14@yandex.ru \\ Паркин Павел Николаевич \\ ФГБОУ ВО «Национальный исследовательский \\ Мордовский государственный университет \\ им. Н.П. Огарева» \\ parkin.p2000@yandex.ru \\ Мелишева Анна Николаевна \\ ФГБОУВО «Начиональный исследовательский \\ Мордовский государственный университет \\ им. Н. П. Огарева» \\ anna.melisheva@yandex.ru
}

Аннотация. Частым осложнением сахарного диабета являются диабетические язвы стопы. Малоэффективное лечение данной патологии представляет собой серьезную медицинскую дилемму как для пациентов, так и для врачей и создает финансовую нагрузку на систему здравоохранения. Несмотря на усилия врачей, хронические диабетические язвы стопы трудно или вовсе не поддаются лечению только с помощью стандартной медицинской помощи. В течение десятилетий амниотическая мембрана человека, состоящая из амниона и хориона, показала высокий терапевтический потенциал, но только современные методы консервации способствовали ее более широкому использованию. Литературные источники свидетельствуют, что амниотическая мембрана эффективна в лечении хронических язв.

Цель этого обзора -по данным литературы оценить эффективность применения амниотической мембраны для лечения диабетических язв стопы совместно со стандартным лечением.

Выводы: в целом обзор клинических исследований показал, что у пациентов, получавших стандартное лечение совместно с амниотической мембраной, скорость заживления язв была выше, чем только при стандартной терапии. Требуются дополнительные испытания, необходимые для изучения 


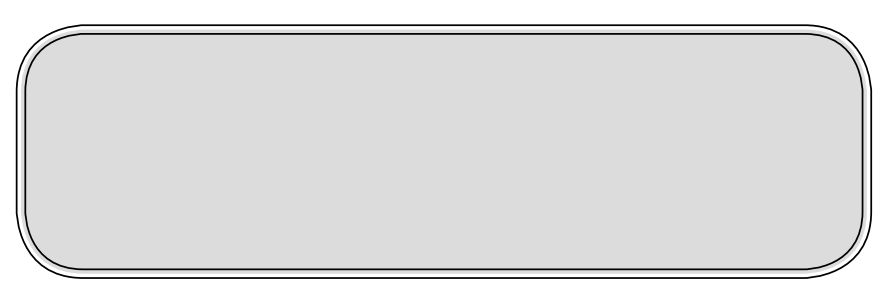

Д иабетические язвы стопы (ДяС) - это сложные хронические раны, которые оказывают значительное долгосрочное влияние на заболеваемость, смертность и качество жизни пациентов.

\section{Ввехение}

Число больных сахарным диабетом (СД) неуклонно растет с каждым годом. По оценкам экспертов, в 2011 году около 366 миллионов человек - 7\% населения мира -страдают СД, причем примерно 80\% из них живут в развивающихся странах. Ожидается, что к 2030 году это число возрастет до 552 миллионов человек (8,3\% населения мира) [2]. Осложнения СД также являются растущей проблемой общественного здравоохранения.

В целом, СД имеет высокий уровень заболеваемости и смертности из-за острых и хронических осложнений, связанных с этим заболеванием. Острые осложнения включают гипогликемию, диабетический кетоацидоз и гиперосмолярную кому. Однако именно хронические осложнения, такие как ишемическая болезнь сердца, заболевания периферических сосудов, нейропатия или почечная нефропатия, вызывают самые высокие показатели заболеваемости.

Распространенным хроническим осложнением СД является так называемая диабетическая стопа, которая возникает главным образом из-за высокого механического давления и / или травмы стопы, а затем заживление ран осложняется нейропатией, васкулопатией и иммунопатией $[3,5,20,21]$.

Диабетическая нейропатия является следствием внутриклеточного накопления глюкозы, что приводит к эндоневральному отеку и неадекватному функционированию $\mathrm{Na}+$ / K+ насоса [19]. Изменение ионного движения на клеточной мембране нерва вызывает снижение скорости проводимости нервного импульса, первоначально провоцирующее снижение тактильной чувствительности и, позднее, отсутствие защитной чувствительности, ухудшающее обнаружение небольших травм, вызывающее начальные изъязвления на ногах [5, 19]. Приблизительно в $80 \%$ случаев ампутаций при диабетической стопе предшествуют диабетические язвы стопы (ДЯС), чего можно было бы избежать путем про- лечебного действия амнион/хорион мембранных продуктов (препаратов или покрытий).

Ключевые слова: Сахарный диабет, амниотическая мембрана, диабетические язвы, стандартная терапия, уход за раной, факторы роста.

филактики, просвещения и периодического мониторинга пациентов.

Диабетические язвы стопы - это сложные хронические раны, которые оказывают долгосрочное влияние на заболеваемость, смертность и качество жизни пациентов СД [8]. Люди с развитием ДЯС подвержены большему риску преждевременной смерти, инфаркта миокарда и смертельного инсульта, чем те, у кого в анамнезе этого осложнения не было. Приблизительно у $25 \%$ людей с диабетом со временем развивается язва нижней конечности [11]. Лечение этих язв остается сложной задачей, так как они медленно заживают и часто рецидивируют. Плохой прогноз ДяС объясняется диабетической ангиопатией, нейропатией и гипергликемией. Задержка заживления язв повышает риск развития тяжелой раневой инфекции и может привести к ампутации конечности [15].Приблизительно у половины людей, перенесших нетравматические ампутации, диагностирован СД, при этом исследования показывают, что до 88\% всех связанных с диабетом ампутаций предшествует язва стопы [26, 27], сравнимая со многими типами рака [27]. Поэтому любое лечение, которое может уменьшить риск ампутации, приветствуется. Основная цель лечения ДЯС состоит в том, чтобы способствовать быстрому и полному заживлению язвы, уменьшить риск развития инфекции, ампутации и других осложнений. Влажные повязки, санация ран и контроль сахара крови являются стандартной терапией при лечении ДяС. Стандартная терапия обычно используется во многих клинических центрах по всему миру.

D.J. Margolisetal [16] изучал использование обычных методов лечения ДяС, такие как санация, снятие давления и применение влажных повязок при дяС. По его данным, частота заживления ран при нейропатических язвах составила всего $24,2 \%$ за 12 недель и $30,9 \%$ за 20 недель.

Руководящие принципы специалистов Европы и США рекомендуют использовать передовые методы лечения ран, если размер диабетической язвы не уменьшается на $40 \%$ или более после 4 недель стандартной терапии [24].Экспертное сообщество рекомендует дополнительную терапию ран, если не удается уменьшить ДЯС (> 50\% площади раны) после минимум 4 недель стандартного лечения [10]. 
Прогресс в лечении ран - использование амниотической мембраны. Амниотическая мембрана находится во внутреннем слое плаценты и состоит из мембран амниона и хориона. Амниотическая мембрана представляет собой тонкий, очень прочный биоматериал; он поддерживает развивающийся плод и амниотическую жидкость на протяжении всей беременности. Амниотические мембраны бессосудисты и не имеют прямого кровоснабжения, и все питательные вещества поставляются путем диффузии из околоплодных вод или из децидуальной оболочки. Амниотическая мембрана также выделяет вещества в амниотическую жидкость и матку, способствующие гомеостазу околоплодных вод и физиологии материнской клетки.

Амнион состоит из эпителиального слоя, слоя базальной мембраны, компактного слоя, слоя фибробластов и промежуточного слоя. Каждый из этих 5 слоев содержит уникальное расположение различных клеток, типов коллагена и структурных белков; вместе они обеспечивают механическую целостность мембраны [17]. Для сравнения, хорион примерно в 4 раза толще амниона и состоит из ретикулярного слоя, слоя базальной мембраны и слоя трофобласта[12, 18].

Амниотическая мембрана содержит многочисленные факторы роста, цитокины и сигнальные молекулы, которые играют важную роль в развитии и беременности плода, а в регенерации тканей.

К ним относятся факторы роста АА и ВB, трансформирующие факторы роста альфа и бета, основной фактор роста фибробластов, эпидермальный фактор роста и гранулоцитарно-колониестимулирующий фактор [12]. Кроме того, интерлейкины 4, 6, 8 и 10 были обнаружены в образцах АМ и предполагается, что их иммуносупрессивные функции могут играть роль в иммунных свойствах продуктов амниотической мембраны, таких как дегидратированная мембрана амниона/хориона человека (dHACM) [12].

Амнион неиммуногенный, и было показано, что он уменьшает воспаление и боль, а также служит матрицей для отложения клеток [12]. В последние годы использование продуктов амниотической мембраны человека в клинических условиях возросло в геометрической прогрессии. Офтальмологи использовали продукты из амниона / хориона для лечения изъязвлений роговицы, поражений конъюнктивы и химических ожогов глаза. В недавних исследованиях[28] изучалась возможность применения продуктов из мембраны амниона / хориона при хронических кожных ранах, включая диабетическую стопу и венозную язву ноги.

Обработанная мембрана амниона / хориона человека (криоконсервированная, дегидратированная или бесклеточная) считается дополнительной терапией для лечения ран. Показана её эффективность в лечении диабетических ран [1, 9], что проявлялась в более быстром заживлении хронических дяС по сравнению с одной стандартной терапией [22]. Фактически, многие исследования показали, что амниотическая мембрана человека обладает свойствами, которые улучшают заживление. Обработанная PURION ${ }^{\circledR}$ обезвоженная мембрана амниона / хориона человека (dHACM) сохраняет биологически активные факторы роста и регуляторные факторы, которые частично отвечают за её клиническую эффективность при заживлении ран [13]. dНАСМ может стимулировать стволовые клетки, полученные из диабетических жировых клеток (ADSC), к миграции, пролиферации и изменению экспрессии цитокинов, что позволяет предположить, что ADSC могут реагировать на dHACM для ускорения заживления диабетических ран. Клеточная амниотическая мембрана (AM) обладает способностью доставлять аутологичные или аллогенные клетки для лечения различных состояний, включая ДяС, дефект роговицы и ожоги кожи. Криоконсервированная амниотическая мембрана человека сохраняет все нативные компоненты, включая жизнеспособные эндогенные клетки, которые могут усиливать ангиогенную активность при хронических ранах [7]. Продукты Amnion в настоящее время доступны и производятся в различных формах в зависимости от их компонентов или методов обработки [28].

Нейропатия приводит к отсутствию защиты стопы, поэтому травмы, способствующие инфицированию, остаются незамеченными. Нейропатия также способствует прогрессированию инфекции. По данным авторов, ДЯС из включенных в исследование были расположены на пальцах ног, передней, средней, задней части стопы и плюсневой кости. Это связано с тем, что из-за потери защитной чувствительности, связанной с нейропатией, появляются биомеханические факторы, которые приводят к деформациям, вызывающим или усугубляющим поражения стопы вследствие повторяющейся травмы [5]. Кроме того, нейропатия может приводить к формированию остеоартропатии Шарко, которая делает повторяющиеся травмы незамеченными, вызывая воспалительные изменения, которые приводят к остеокластической реакции и деформации стопы [25]. Эти деформации вызывают анатомические изменения в стопах, которые предрасполагают к образованию язв на передней части стопы, пальцах ног и плюсневых костей [29].

Важно отметить, что в группе больных с применением амниотических мембран язва имеет вероятность заживления в 2,32. раз больше, чем в контрольной группе. В исследовании, проведенном С.M. Zelenи соавт. [29], 
этот результат еще более очевиден. В основной группе (амнион) среди 32 пациентов с язвами, раны зажили почти у всех (31 человека). В контрольной группе зажили только 18 из 35 ран. Все исследования, включенные в метаанализ, сравнивают амнион со стандартными обычными повязками, которые поддерживают влажную микроокружающую среду, такую как альгинат и альгинатколлагена. Существует тенденция, что время заживления ран, обработанных амнионом, происходит на 32 дня быстрее, чем те, которые заживают под обычными повязками $[29,14]$.

Обсуждение обзора показывают, что АМ эффективна при лечении хронических ДЯС, когда она сочетается со стандартной терапией. Несколько более ранних исследований показали большую эффективность комбинированного лечения ДЯС амниотической мембраной +применение стандартной терапии при заживлении сложных ран. Эта комбинированная стратегия лечения позволяет закрыть рану быстрее, чем применение только стандартной терапии, что способствует быстрому и полному заживлению, снижает риск развития инфекции, ампутации и других осложнений.

Внутренние свойства амниона объясняют его эффективность в улучшении заживления хронических ДяС. Амниотическая мембрана положительно влияет на основные физиологические процессы, тесно связанные с заживлением ран: пролиферацию клеток, воспаление, активность металлопротеиназы и рекрутирование клеток-предшественников [13]. Амниотическая мембрана способствует реваскуляризации и заживлению тканей в слабо кровоснабжаемых хронических ранах, поскольку она содержит ангиогенный фактор роста, который сохраняет биологическую активность. Низкая иммуногенность АМ допускает её аллогенное использование. Она действует как физический барьер против бактериального загрязнения, а также создает влажную среду, необходимую для заживления. Кроме того, амнион уменьшает боль и обладает противовоспалительной, антифиброзной и антимикробной активностью, которая способствует заживлению ран [7].

Анализ показывает, что при использовании АМ в качестве адъювантной терапии у пациентов с ДяС оптимальное время для оценки заживления составляет 4 и 12 недель. Этот результат положительно коррелирует с результатами других авторов. Следует отметить, что когда в качестве лечения используется только стандартная терапия, рана, площадь которой не уменьшается на $\geq 40 \%$ через 4 недели, имеет мало шансов на заживление через 12 недель. Раннее уменьшение размера раны указывает на хороший прогноз. Фактически 4 недели наблюдения являются надежным предиктором заживления через 12 недель [23].
Кроме того, препараты с АМ являются относительно недорогими и даже более эффективными, чем традиционная терапия, могут быть полезны в странах с низким уровнем дохода.

\section{Зак^ючение и вывоАы}

Этот обзор включает исследования, проведенные в разных странах. Результаты показывают, что АМ человека + стандартная терапия лечит ДЯС значительно эффективнее, чем только стандартная терапия. Основываясь на текущих данных этого мета-анализа и предыдущих результатах, предполагаем, что когда используется АМ при лечении пациентов с ДЯС, оптимальное время для оценки заживления должно составлять 4 и 12 недель. Однако необходимы исследования для проверки результатов и оценки заживления в инфицированных диабетических язвах.

Применение человеческих амниотических мембран в заживлении ран восходит к 1940-м годам, когда офтальмологи начали исследовать их полезность при стойких дефектах роговицы. Многочисленные цитокины и факторы роста, обнаруженные в плаценте, делают амнион / хориональные мембраны полезными для заживления ран и тканей. [12 17]. Развитие технических достижений в обработке и консервации dНАСМ позволяет хранить трансплантаты в течение нескольких месяцев, что делает возможным их применение как при неотложных, так и в плановых ситуациях [12].

Как свежие, так и консервированные мембраны амниона / хориона изучены при лечении широкого спектра ран, включая ожоги, диабетические язвы, свищи, глазные дефекты и венозные язвы. Причем исследования варьировались от единичных случаев до рандомизированных контролируемых исследований [17]. Аллотрансплантаты амниона / хориона обеспечивают существенное преимущество при лечении трудно заживающих свищей без рецидива дефекта. Что касается диабетических и венозных язв, то использование амниона / хориона мембраны в дополнение к стандартной терапии были более эффективными, чем только стандартная терапия.

Большинство исследований сосредоточено на применение dHACM, и мало публикаций о конкурирующих продуктах амниотической мембраны. Необходимы подтверждающие доказательства клинической полезности dHACM; тем не менее, дополнительные исследования, в которых рассматриваются другие продукты dHACM, будут полезны как для повышения общих знаний o dHACM, так и для того, чтобы врачи принимали обоснованные решения при выборе продуктов для лечения ран. 


\section{ЛИТЕРАТУРА}

1. Abdo R. J. Treatment of diabetic foot ulcers with dehydrated amniotic membrane allograft: a prospective case series. /Abdo R.J. // J Wound Care. — Vol. 25(7). — 2016. - P. 4-9.

2. Bakker K. The development of global consensus guidelines on the management and prevention of the diabetic foot 2011. / Bakker K., Schaper N. C. //Diabetes Metab Res Rev. - Vol. 28. - 2012.—P. 116-118.

3. Boulton A. J. The global burden of diabetic foot disease. /Boulton A.J., Vileikyte L., Ragnarson-Tennvall G., Apelqvist J.//Lancet 2005.—Vol. 366(9498).— P. 1719_ 1724.

4. Brantley J. N. Use of placental membranes for the treatment of chronic diabetic foot ulcers. /Brantley J.N., Verla T. D. // Adv Wound Care. — Vol. 4(9). — 2015.— P. 545-559.

5. Bus S. A. Evaluation and optimization of therapeutic footwear for neuropathic diabetic foot patients using in-shoe plantar pressure analysis./Bus S.A., Haspels R., Busch-Westbroek T.E //Diabetes Care 2011.—Vol. 34(7). - P. 1595-1600.

6. Dua H. S. The amniotic membrane in ophthalmology. /Dua H.S., Gomes J. A., King A. J., Maharajan V. S. //Surv0phthalmol. — Vol.49(1).— 2004.—P. 51-77.

7. Duan-Arnold Y. Angiogenic potential of cryopreserved amniotic membrane is enhanced through retention of all tissue components in their native state. /DuanArnold Y., Uveges T. E., Gyurdieva A., Johnson A., Danilkovitch A. //Adv Wound Care. — Vol. 4(9). — 2015. — P. 513-522.

8. Haria J. M. Life with diabetic foot ulcer — a cross sectional study. /Haria J.M., Singh V. K., Jain S. K. //Int J Sci Study. — Vol.1(6). — 2014. — P. 33-35.

9. Hawkins B. The use of micronized dehydrated human amnion/chorion membrane allograft for the treatment of diabetic foot ulcers: a case series. /Hawkins B. // Wounds CompendClin Res Pract. - Vol. 28(5). - 2016. - P. 152-157.

10. Hingorani A. The management of diabetic foot: a clinical practice guideline by the Society for Vascular Surgery in collaboration with the American Podiatric Medical Association and the Society for Vascular Medicine. /Hingorani A., LaMuraglia G.M., Henke P., Meissner M. H., Loretz L., Zinszer K. M., Driver V. R., Frykberg R., Carman T. L., Marston W., Mills J. L., Sr, Murad M. H. // J Vasc Surg. — Vol. 63(2).—2016. — P. 3-21.

11. Kirsner R.S. Comparative effectiveness of a bioengineered living cellular construct vs. a dehydrated human amniotic membrane allograft for the treatment of diabetic foot ulcers in a real world setting. /Kirsner R.S., Sabolinski M. L., Parsons N. B., Skornicki M., Mars-ton W.A. //Wound Repair Regen. — Vol. 23(5).— 2015.- P. 737-744.

12. Koob T. J. Biological properties of dehydrated human amnion/chorion composite graft: implications for chronic wound healing [published online ahead of print August 1, 2013]. /Koob T.J., Rennert R., Zabek N., et al. //Int Wound J.— Vol. 10(5).— 2013.— P. 493-500.

13. Koob T. J. Biological properties of dehydrated human amnion/chorion composite graft: implications for chronic wound healing. /Koob T.J., Rennert R., Zabek N., Massee M., Lim J. J., Temenoff J. S., Li W.W., Gurtner G. //Int Wound J.— Vol. 10(5). — 2013. — P. 493-500.

14. Lavery L. A. The efficacy and safety of Grafix (R) for the treatment of chronic diabetic foot ulcers: results of a multi-centre, controlled, randomised, blinded, clinical trial. /Lavery L.A., Fulmer J., Shebetka K. A., Regulski M., Vayser D., Fried D., Kashefsky H., Owings T. M., Nadarajah J. // Int Wound J.— Vol. 11(5).—2014.— P. 554-560.

15. Lipsky B. A. Infectious Diseases Society of America clinical practice guideline for the diagnosis and treatment of diabetic foot infections. /Lipsky B.A., Berendt A. R., Cornia P. B., Pile J. C., Peters E. J., Armstrong D. G., Deery H. G., Embil J. M., Joseph W. S., Karchmer A. W., Pinzur M. S., Senneville E. // Clin Infect Dis.—Vol. 54(12).— 2012. - P. 132-173.

16. Margolis D. J. Healing of diabetic neuropathic foot ulcers receiving standard treatment. A meta-analysis. /19. Margolis D. J., Kantor J., Berlin J. A. // Diabetes Care. Vol.22(5). - 1999. - P. 692-695.

17. Niknejad H. Properties of the amniotic membrane for potential use in tissue engineering./Niknejad H., Peirovi H.,JorjaniM,.Ahmadiani A., Ghanavi J., Seifalian A. M.// Eur Cell Mater. - Vol. 15. - 2008. — P. 88-99.

18. Oyen M. L. Mechanical failure of human fetal membrane tissues. /0yen M.L., Cook R. F., Calvin S. E. //J Mater Sci Mater Med. — Vol. 15(6). — 2004. — P. 651-658.

19. Pasnoor M. Diabetic neuropathy part 1: overview and symmetric phenotypes. /Pasnoor M., Dimackie M., Kludding P., Bahoon R. J. //NeurolClin 2013.— Vol. 31(2). - P. 425-445.

20. Pinzur M. S. Diabetic peripheral neuropathy. /Pinzur M.S. // Foot Ankle Clin 2011.—Vol.16(2). — P. 345-349.

21. Prompers $L$. Prediction of outcome in individuals with diabetic foot ulcers: focus on the differences between individuals with and without peripheral arterial disease. The EURODIALE Study./Prompers L., Schaper N., Apelqvist J. et al. //Diabetologia. — Vol. 51(5). — 2008. — P. 747-755.

22. Rosenblum B.I. A retrospective case series of a dehydrated amniotic membrane allograft for treatment of unresolved diabetic foot ulcers. /35. Rosenblum B. I. // J Am Podiatr Med Assoc. — Vol. 106(5). — 2016. — P. 328-337.

23. Sheehan P. Percent change in wound area of diabetic foot ulcers over a 4-week period is a robust predictor of complete healing in a 12 -week prospective trial. /50. Sheehan P., Jones P., Giurini J. M., Caselli A., Veves A//PlastReconstr Surg. — Vol. 117(7). — 2006. — P. 239-244.

24. Steed D. L. Guidelines for the treatment of diabetic ulcers. /Steed D.L., Attinger C., Colaizzi T., Crossland M., Franz M., Harkless L., Johnson A., Moosa H., Robson M., Serena T., Sheehan P., Veves A., Wiersma-Bryant L.// Wound Repair Regen. - Vol. 14(6). - 2006. — P. 680-692.

25. Steed D. L. Guidelines for the treatment of diabetic ulcers. /Steed D.L., Attinger C., Colaizzi T. et al. // Wound Repair Regen 2006. -Vol.14(6). — P. 680-692.

26. Thorud J.C. Mortality after nontraumatic major amputation among patients with diabetes and peripheral vascular disease: a systematic review. /Thorud J.C., Plemmons B., Buckley C. J., Shibuya N., Jupiter D. C. //J Foot Ankle Surg. — Vol. 55(3). — 2016. — P. 591-599.

27. Wilbek T. E. The diabetic foot in a multidisciplinary team setting. Number of amputations below ankle level and mortality. /Wilbek T.E., Jansen R. B., Jorgensen B., Svendsen 0. L. // ExpClinEndocrinol Diabetes. — Vol.124(9).— 2016. — P. 535-540. 
28. Zelen C.M. A prospective, randomised comparative study of weekly versus biweekly application of dehydrated human amnion/chorion membrane allograft in the management of diabetic foot ulcers [published online ahead of print February 21, 2014]. /Zelen C.M., Serena T. E., Snyder R. J.//Int Wound J.— Vol. 11(2).— 2014.- P. 122-128.

29. Zelen C. M. Treatment of chronic diabetic lower extremity ulcers with advanced therapies: a prospective, randomised, controlled, multi-centre comparative study examining clinical efficacy and cost. /Zelen C.M., Serena T. E., Gould L. et al. //Int Wound J 2016. — Vol. 13(2). — P. $272-282$.

с Р Родин Олег Васильевич ( rodin1oleg@gmail.com ), Колосунин Иван Александрович ( kolosunin_ivan@mail.ru ), Козлов Сергей Александрович ( kozlovsa14@yandex.ru ), Паркин Павел Николаевич ( parkin.p2000@yandex.ru),

Мелишева Анна Николаевна ( anna.melisheva@yandex.ru ).

Журнал «Современная наука: актуальные проблемы теории и практики»

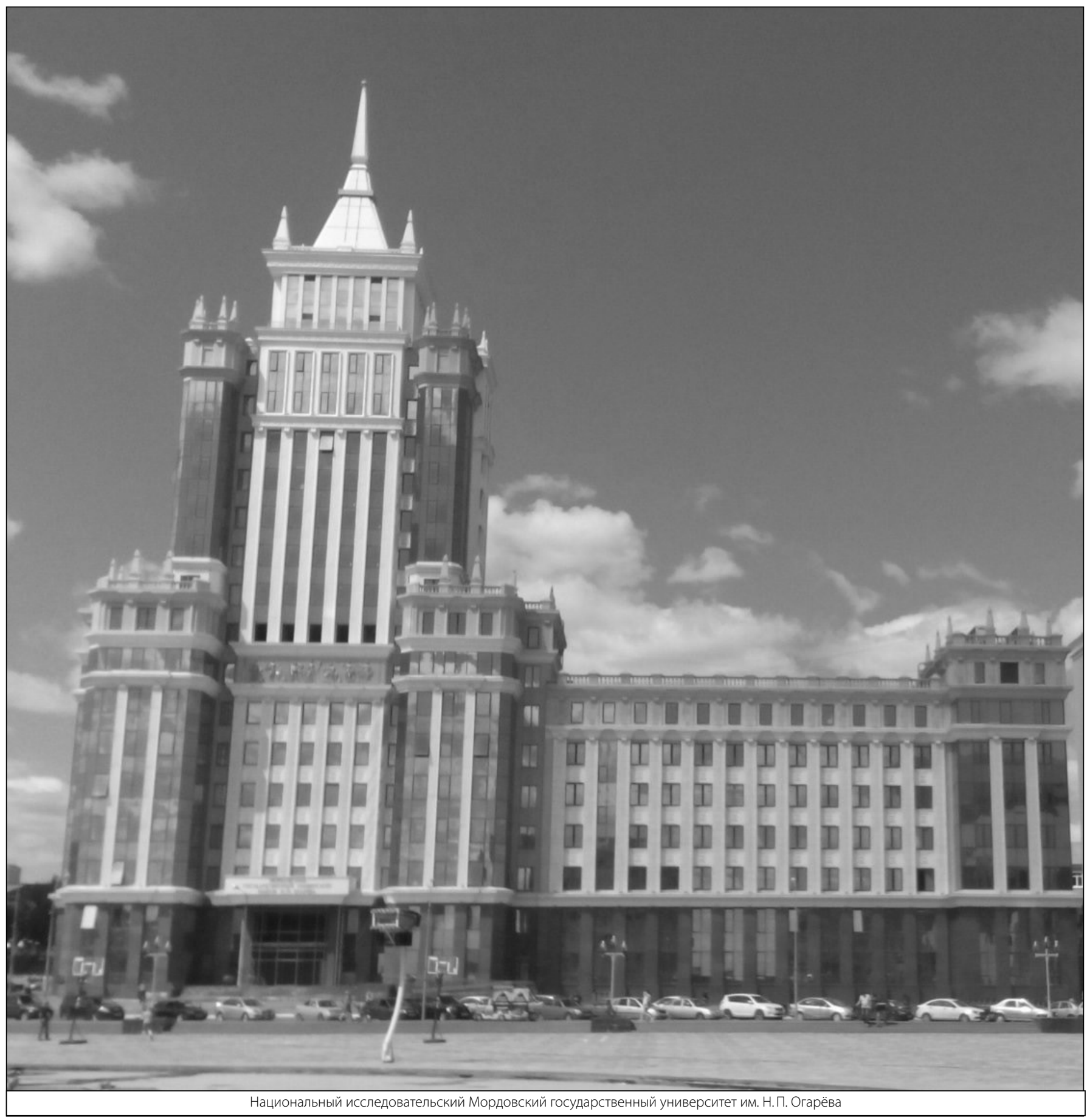

